\title{
Subcellular localization of MS4A13 isoform 2 in mouse spermatozoa
}

\author{
Takane Kaneko ${ }^{1}$, Kiyotaka Toshimori ${ }^{2}$ and Hiroshi lida ${ }^{1}$ \\ ${ }^{1}$ Laboratory of Zoology, Graduate School of Agriculture, Kyushu University, Fukuoka, Japan and ${ }^{2}$ Future Medicine \\ Research Center and Department of Reproductive Biology and Medicine, Graduate School of Medicine, Chiba \\ University, Chiba, Japan
}

Correspondence should be addressed to T Kaneko or K Toshimori or H lida; Email: takane@agr.kyushu-u.ac.jp or ktoshi@faculty. chiba-u.jp or iidahiro@agr.kyushu-u.ac.jp

\begin{abstract}
To identify upregulated genes during the development of spermatozoa, we performed PCR-selected subtraction analysis of testes RNA samples from 10-day-old and 12-week-old shrews. A transcript, highly homologous to two mouse transcripts, Ms4a13-1 and Ms4a132, was differentially regulated. Ms4a13-2, but not Ms4a13-1, was shown to be primarily expressed in mouse testes in an agedependent manner. Ms4a13-2 cDNA contains an open-reading frame of 522 nucleotides, encoding a protein of 174 amino acids, with predicted molecular mass, 19,345 Da. MS4A13-2 protein was expressed along the periphery of nuclei of round and elongated spermatids (steps 3-16) in adult mouse testes, and in the equatorial region of the heads of fresh mature mouse spermatozoa. In addition, MS4A13-2 was found to localize to the outer acrosomal membrane in the equatorial region of heads in fresh spermatozoa. In acrosome-reacted spermatozoa, the MS4A13-2 expression extended to the entire sperm head including the postacrosomal region and acrosomal cap. MS4A family proteins are known to facilitate intracellular protein-protein interactions as ion channel/adaptor proteins by oligomerization, and have important regulatory roles in cellular growth, survival and activation. We report that the MS4A family member, MS4A13-2, may form oligomers in sperm membranes, which may be involved in an interaction with the zona pellucida or cumulus during fertilization.

Reproduction (2017) 154 843-857
\end{abstract}

\section{Introduction}

In many mammals, the sperm-oocyte interaction involves a sequence of processes, including passage of sperm through cumulus cells, binding of sperm to the zona pellucida, penetration of sperm through the zona pellucida and adhesion and fusion of the sperm and oocyte plasma membranes.

In contrast to the diffuse hyaluronic acid matrixrich structure in many mammals, in the musk shrew, Suncus murinus, the cumulus appears as a compact hyaluronidase-insensitive ball of cells, devoid of intercellular matrix (Bedford et al. 1994). S. murinus spermatozoa consistently bind to the surface of an outer cumulus cell through the face of the intact sperm head, followed by fusion of the sperm plasma and outer acrosomal membranes at this point. Thereafter, individual spermatozoa without an acrosome have been observed within a cumulus cell displaying signs of necrosis. Loss of the acrosome exposes an apical body/perforatorium covered with barbs, which appears to assist in binding of the fertilizing spermatozoa to the zona pellucida. Finally, a spermatozoon fuses with the oocyte plasma membrane (Kaneko et al. 2001).
Although the cellular events of mammalian fertilization are not fully understood at the molecular level despite numerous studies, they depend on the numerous different binding patterns of the molecules on the surface of the sperm head (Stein et al. 2004, Okabe 2014).

There are more than 16 members of the human and mouse membrane-spanning 4-domains, subfamily A (MS4A) gene family, which map to clusters on human chromosome 11q12-13 and mouse chromosome 19, respectively (Ishibashi et al. 2001, Liang \& Tedder 2001, Liang et al. 2001). The MS4A gene family encodes various cell membrane proteins, the majority of which characteristically contain four membrane-spanning regions and $\mathrm{N}$ - and $\mathrm{C}$-terminal cytoplasmic domains (Ishibashi et al. 2001, Zuccolo et al. 2010, Eon Kuek et al. 2016).

MS4A1 (CD20) is involved in an increase in $\mathrm{Ca}^{2+}$ conductance, possibly by acting as an ion channel (Bubien et al. 1993); this protein can homo-oligomerize into tetramers and physically associate with the antigenbinding component of B cell receptors to positively regulate $B$ cell receptor-induced cytoplasmic $\mathrm{Ca}^{2+}$ mobilization (Polyak et al. 2008). MS4A2 (FCRB) is 
a component of the high-affinity $\lg E$ receptor and associates with FceRl $\alpha$ and FCR $\gamma$ to form a tetrameric receptor complex $(\alpha \beta \gamma 2)$ expressed at high density on mast cells and basophils (Dombrowicz et al. 1998), resulting in amplification of IgE-mediated signals (Lin et al. 1996). MS4A1 and MS4A2 are associated with the activation and proliferation of B lymphocytes (Tedder \& Engel 1994) and mast cells and basophils (Cruse et al. 2010), respectively. Many MS4A family members, including MS4A3 (HTm4; Donato et al. 2002, Chinami et al. 2005, Kutok et al. 2011) and MS4A4B (Xu et al. 2010), regulate the cell cycle and act as chemosensors expressed in necklace sensory neurons (Greer et al. 2016). Abnormal or absent MS4A protein expression has been observed in various cancers (Bangur et al. 2004, Koslowski et al. 2008, Kutok et al. 2011), while MS4A4 and MS4A6 are associated with the development of lateonset Alzheimer's disease (Hollingworth et al. 2011, $\mathrm{Naj}$ et al. 2011), and polymorphisms of MS4A2 are commonly associated with atopy (Shirakawa et al. 1994).

MS4A5 (TETM4; Hulett et al. 2001), MS4A13 (NYD-SP21; Turner et al. 2008) and MS4A14 (SP3111; Xu et al. 2014) are testis-specific proteins, and MS4A14 is thought to be expressed in the acrosome and the midpiece of the flagella in mature spermatozoa, and to be involved in fertilization. MS4A13 is specifically expressed in the testis (Turner et al. 2008); however, its precise localization and function in spermatozoa are yet to be reported.

In this study, we focused on the mouse, because of the ease of obtaining samples for experiments, rather than $S$. murinus, for which various interesting features have been observed in the process of fertilization, and may help to elucidate the diversity of mammalian fertilization. We aimed to identify genes differentially regulated in sperm development to determine the precise expression pattern of MS4A13-2 in mouse testes and spermatozoa before and after the acrosome reaction and to reveal the role of MS4A13-2 in fertilization.

\section{Materials and methods}

\footnotetext{
Animals

Investigations were conducted in accordance with the National Research Council Publication, Guide for Care and Use of Laboratory Animals. The Animal Experiment Committee of Kyushu University investigated our research plan and granted permission for the animal experiments (document numbers A27-058-1 and A29-022-0). Male shrews (S. murinus) of three months or more in age, originating from stocks caught in Katmandu, were raised at Kyushu University or at the Laboratory of Animal Management and Resources, Department of Zoology, Faculty of Science, Okayama University of Science. ddY mice were obtained from Kyudo Company (Fukuoka, JP) or bred at Kyushu University.
}

\section{RNA isolation and PCR-selected subtraction analysis}

Total RNA samples were isolated from testes of 10-day-old and 12-week-old isoflurane (5\%)-anesthetized shrews using a QuickPrep Total RNA Extraction Kit (GE Healthcare UK Ltd). Poly(A)+ mRNA was purified using an mRNA Purification Kit (GE Healthcare UK Ltd.) and used for PCR-selected subtraction analysis to identify differentially expressed cDNAs, performed with the Clontech PCR-Select cDNA Subtraction Kit (Clontech); cDNAs from the testis of 12-week-old and 10-day-old shrews were used as 'tester' and 'driver' samples, respectively. Subtracted PCR products were cloned into the pGEM-T easy vector (Promega Corp) and sequenced using an ABI PRISM 377 DNA Sequencer (Applied Biosystems), following the manufacturer's instructions. Generated sequences were submitted to BLAST searches of the National Center for Biotechnology Information (NCBI, http://www.ncbi. nlm.nih.gov)-NR database and unpublished Suncus genome resource (currently undergoing preparation for publication) to determine the identity of clones.

\section{RNA isolation, $C D N A$ synthesis and reverse transcription (RT)-PCR}

Total RNA samples from the testis, epididymis, intestine, kidney, spleen, liver and heart of 12-week-old isofluraneanesthetized ddY mice were isolated using the QuickPrep Total RNA Extraction Kit (GE Healthcare UK Ltd.). Total RNA was also isolated from the testes of 1-, 2-, 3- and 12-week-old mice. First-strand cDNA was synthesized from $2 \mu \mathrm{g}$ of total RNA, using a PrimeScript first-strand cDNA synthesis Kit (Takara Biotech.) with oligo-(dT) primers. The reverse-transcribed cDNA was used as a PCR template to amplify gene sequences. PCR was performed using GoTaq DNA polymerase (Promega). Primers to amplify the glyceraldehyde-3-phosphate dehydrogenase (G3pdh) gene were 5'-TGAAGGTCGGTGTCAACGGATTTGGC-3' (forward) and 5'-CATGTAGGCCATGAGGTCCACCAC-3' (reverse). The primers used to amplify the mouse openreading frames (ORFs), Ms4a13-1 and Ms4a13-2, were 5'-ATGGAATGTAGAAATCCAAAAGTATC-3' (forward) and 5'-AGGAGTTGCCTTCCACTACTTC-3' (reverse). PCR products were analyzed by agarose gel electrophoresis.

\section{Antibody production}

Two peptides, VSYRNYGQAKLGR and AGNQEETLESVTEVVEGNS, derived from the hydrophilic regions of the putative extracellular region and C-terminus, respectively, of mouse MS4A13-2 were used to raise antibodies. The peptides were coupled to keyhole limpet hemocyanin (Pierce), dissolved in sterilized water, emulsified with Freund's adjuvant and injected into a rabbit. Antisera were collected within 2 weeks after the five injections. Affinity purification of the antibodies was carried out over matrix-immobilized peptide coupled to 2-fluoro-1-methylpyridinium toluene-4sulfonate-activated Sephadex (Seikagaku Kogyo, Chiyoda-ku, Tokyo, Japan). The concentrations of two purified antibodies were estimated using a protein assay. 


\section{Specificity of the anti-MS4A13-2 antibodies}

Mouse Ms4a13-2 mRNA contains an ORF of 522 nucleotides encoding 174 amino acids (AAs). Nucleotides encoding the carboxy-terminus (AAs 75-174) of MS4A132, with a predicted molecular weight of approximately $11.2 \mathrm{kDa}$, were PCR-amplified using the primers 5'-GCCAAGCTTGTAATGGCAGCAAAATATCAAAGTAGAC-3' (forward)

and 5'-GAGGGATCCGAGTTGCCTTCCACTACTTC-3' (reverse). The PCR product was then digested with HindIII and BamHI and cloned in-frame into the pTagRFP-N expression vector (Evrogen JSC, Moscow, Russia). The PCR product sequence was confirmed by Sanger sequencing using an ABI PRISM 377 DNA Sequencer (Applied Biosystems).

Plasmids were transfected into COS7 cells, using Lipofectamine 2000 reagent (Invitrogen), following the manufacturer's instructions. After $24 \mathrm{~h}$ of culture in Dulbecco's modified Eagle's medium (Wako Pure Chemical Industries) supplemented with $10 \%(\mathrm{v} / \mathrm{v})$ fetal bovine serum (SigmaAldrich), transfected cells were either lysed directly in SDS-PAGE buffer $(62.5 \mathrm{mM}$ Tris- $\mathrm{HCl} ; 2 \%(\mathrm{w} / \mathrm{v})$ SDS; $10 \%$ (v/v) glycerol; $0.005 \%(\mathrm{w} / \mathrm{v})$ bromophenol blue; 5\% (v/v) 2-Mercaptoethanol) for electrophoresis and immunoblot analysis or fixed and examined under a fluorescence microscope (Leica DM RXA; Leica Microsystems). Non-transfected COS7 cells were used as controls.

For immunoblot analysis, control and transfected COS7 cells prepared for SDS-PAGE were separated by electrophoresis on $15 \%(\mathrm{w} / \mathrm{v})$ acrylamide gels; separated proteins were either stained with Coomassie brilliant blue $(40 \%$ (v/v) methanol; $10 \%(\mathrm{v} / \mathrm{v})$ acetic acid; $0.1 \%(\mathrm{w} / \mathrm{v})$ Coomassie brilliant blue R250) or transferred to PVDF membranes (Hybond-P; GE Healthcare UK). The membranes were incubated for $2 \mathrm{~h}$ with either a polyclonal anti-RFP-Tag antibody (Invitrogen) diluted 1:5000, or each anti-MS4A13-2 antibody diluted 1:5000, in blocking buffer (phosphate-buffered saline (PBS) containing $5 \%(\mathrm{w} / \mathrm{v})$ non-fat milk and $0.05 \%(\mathrm{v} / \mathrm{v})$ Tween-20), followed by incubation with anti-rabbit IgG conjugated with HRP (BioRad) diluted 1:2000 in the same buffer. Antigen-antibody complexes were visualized using an ECL-Plus detection Kit (BioRad).

For immunofluorescence microscopy, control and transfected COS7 cells were fixed using $4 \%(\mathrm{w} / \mathrm{v})$ paraformaldehyde in PBS at $4{ }^{\circ} \mathrm{C}$, washed in PBS and treated with $0.1 \%(\mathrm{v} / \mathrm{v})$ Triton $X-100$ for $5 \mathrm{~min}$. Cells were then were stained with each antiMS4A13-2 antibody diluted 1:200, followed by incubation with FITC-conjugated goat anti-rabbit IgG (GE Healthcare UK). For nuclear staining, immunostained samples were incubated for 30 min with PBS containing Hoechst 33342. Samples were then washed with PBS before examination under a fluorescence microscope (Olympus BX-50; Olympus Optical, or Leica DM RXA). As a control, the two anti-MS4A13-2 antibodies were substituted with pre-immune rabbit sera.

\section{Immunoblot analyses of mouse testis}

Testes of isoflurane-anesthetized adult mice were immersed in PBS on ice, and capsules (tunica albuginea) torn away using tweezers. Seminiferous tubules released from testes were untangled and washed several times in PBS at $4{ }^{\circ} \mathrm{C}$ with gentle agitation to remove interstitial cells. Seminiferous tubules were homogenized and extracted in RIPA buffer (50 mM Tris, pH 7.2; $1 \mathrm{mM}$ EDTA; $0.1 \%(\mathrm{w} / \mathrm{v})$ SDS; $0.1 \%(\mathrm{w} / \mathrm{v})$ Na deoxycholate; $1 \%(\mathrm{v} / \mathrm{v})$ Nonidet P-40) plus protease inhibitor cocktail (Roche Diagnostics $\mathrm{GmbH}$ ), followed by centrifugation at 20,000 $\mathrm{g}$ at $4^{\circ} \mathrm{C}$ for $20 \mathrm{~min}$. Clarified supernatants in RIPA buffer were used as samples for immunoblot analysis with the anti-MS4A13-2 antibody (extracellular region) and immunoprecipitation with the anti-MS4A13-2 antibody (C-terminus). Samples for immunoprecipitation were incubated with either $0.003 \%$ (w/v) anti-MS4A13-2 antibody (C-terminus) or pre-immune serum for $12 \mathrm{~h}$ at $4{ }^{\circ} \mathrm{C}$ with mild agitation. Protein A-agarose $(0.05 \%(\mathrm{w} / \mathrm{v})$; Roche Diagnostics $\mathrm{GmbH})$ was then added, and incubation continued for $4 \mathrm{~h}$ at $4^{\circ} \mathrm{C}$. The resultant protein A-agarose-antibody-antigen complexes were washed five times with RIPA buffer, and twice with $50 \mathrm{mM}$ Tris-Cl ( $\mathrm{pH}$ 6.9). After washing, antigen was eluted from the beads using SDSPAGE sample buffer.

Clarified supernatant in RIPA buffer and immunoprecipitated proteins were separated by SDS-PAGE on a $15 \%(\mathrm{w} / \mathrm{v})$ acrylamide gel and either stained with Coomassie brilliant blue or transferred to PVDF membranes. The membranes from clarified supernatant in RIPA buffer and immunoprecipitated proteins were incubated for $2 \mathrm{~h}$ with anti-MS4A13-2 antibody (extracellular region), and for $3 \mathrm{~h}$ with anti-MS4A13-2 antibody (C-terminus), respectively, diluted 1:5000 with blocking buffer, followed by incubation with HRP-conjugated goat anti-rabbit IgG (BioRad), and HRP-conjugated protein G (BioRad), respectively, diluted 1:2000 in the same buffer. Antigen-antibody complexes were visualized using an ECLPlus detection Kit.

\section{Immunoblot analyses of mouse spermatozoa from epididymides}

Spermatozoa collected from the caput and cauda epididymides of adult mice were purified by Percoll density gradient centrifugation, as reported previously (Awano et al. 1993). Samples were then dissolved in SDS-PAGE buffer for electrophoresis.

Samples prepared for SDS-PAGE were separated on 15\% $(\mathrm{w} / \mathrm{v})$ acrylamide gels and either stained with Coomassie brilliant blue or transferred to PVDF membranes. The membranes were incubated for $2 \mathrm{~h}$ with anti-MS4A13-2 antibody (extracellular region or C-terminus) diluted 1:5000 in blocking buffer, followed by incubation with HRP-conjugated goat anti-rabbit IgG diluted $1: 2000$ in the same buffer. Antigen-antibody complexes were visualized using an ECLPlus detection Kit.

\section{Solubilization of sperm flagella, heads and membranes}

Purified spermatozoa were diluted in PBS and probesonicated (TOMY UR-150P; Tominaga Works, Tokyo, Japan) at maximum power on ice for three $10 \mathrm{~s}$ bursts to separate sperm heads from flagella. The extent of cell breakage was monitored microscopically. Sonicated samples suspended in PBS containing $0.9 \mathrm{M}$ sucrose were layered onto $2.05 \mathrm{M}$ 
sucrose in $10 \mathrm{mM}$ Tris- $\mathrm{Cl}$ (pH 7.0), and onto $2.2 \mathrm{M}$ sucrose in $10 \mathrm{mM}$ Tris-Cl. The samples were centrifuged at $100,000 \mathrm{~g}$ for $60 \mathrm{~min}$ at $4^{\circ} \mathrm{C}$. The band at the interface of $0.9 / 2.05 \mathrm{M}$ sucrose was collected as the flagella fraction and pellets at the bottom of tubes were collected as the sperm head fraction. Samples were washed once in PBS and subjected to a second round of sucrose-density centrifugation for further purification. Highly purified flagella and sperm heads were extracted for $1 \mathrm{~h}$ in RIPA buffer, after which samples were centrifuged for $15 \mathrm{~min}$ at $20,000 \mathrm{~g}$ to separate extracts from undissolved pellets. Supernatants were dissolved in SDS-PAGE buffer for electrophoresis. An aliquot of probe-sonicated spermatozoa was centrifuged for $10 \mathrm{~min}$ at $1000 \mathrm{~g}$, followed by $15 \mathrm{~min}$ at $5000 \mathrm{~g}$ twice. Resultant supernatants, in which neither nuclei nor flagella contamination were found, were further centrifuged at $100,000 \mathrm{~g}$ for $60 \mathrm{~min}$ at $4^{\circ} \mathrm{C}$ to obtain the membrane fraction (mainly containing plasma membrane), which was dissolved in SDS-PAGE buffer for electrophoresis. Samples were processed for immunoblot analysis, as described earlier.

\section{Immunohistochemistry}

Caput and cauda epididymides and testes of adult mice were fixed in $4 \%(\mathrm{w} / \mathrm{v})$ paraformaldehyde in PBS at $4{ }^{\circ} \mathrm{C}$ for $4 \mathrm{~h}$, washed thrice in PBS, incubated in PBS containing $50 \mathrm{mM}$ $\mathrm{NH}_{4} \mathrm{Cl}$ for $30 \mathrm{~min}$ and then rinsed in PBS. After infiltration with $20 \%(\mathrm{w} / \mathrm{v})$ sucrose in PBS, they were immersed in OCT compound (Tissue-Tek; Miles, Inc., Elkhart, IN, USA) and immediately frozen in liquid nitrogen. Frozen sections $(10 \mu \mathrm{m})$ were cut using a cryostat (CM1850; Leica Biosystems), and then attached to poly-L-lysine (Sigma-Aldrich)-coated glass slides for immunolabeling.

Fresh spermatozoa collected from caput and cauda epididymides of adult mice were fixed in $4 \%(\mathrm{w} / \mathrm{v})$ paraformaldehyde in PBS at $4{ }^{\circ} \mathrm{C}$ for $1 \mathrm{~h}$, washed in PBS and then mounted on poly-L-lysine-coated glass slides for immunolabeling.

The sections and spermatozoa on glass slides were washed in PBS, exposed to $0.1 \%$ Triton X-100 in PBS and then immunostained with the anti-MS4A13-2 antibody (extracellular region or C-terminus) diluted 1:200 with blocking buffer, followed by incubation with goat antirabbit IgG conjugated with fluorescein isothiocyanate (Cy3) diluted 1:1000 in the same buffer. For double immunostaining, sections and spermatozoa were stained with the anti-MS4A13-2 antibody (C-terminus) and the monoclonal anti-MN7 antibody diluted 1:200 in blocking buffer, followed by incubation for with goat anti-rabbit IgG conjugated with Cy3 and anti-mouse IgG conjugated with FITC. The 90-kDa acrosome protein recognized by the MN7 antibody localizes to the acrosomal vesicle, including the acrosomal granule in early round spermatids, and at the anterior acrosome, but not at the equatorial region in elongated spermatids and mature spermatozoa (Tanii et al. 1994, Ito \& Toshimori 2016). MN7 antigen can therefore be used as a marker protein for the acrosome, but not for the equatorial region. Alternatively, pure Arachis hypogaea lectin conjugated with FITC (FITC-PNA; 1 mg/ mL, EY Lab, San Mateo, CA, USA) was used to label acrosomes of spermatozoa instead of the monoclonal anti-MN7 antibody.
For nuclear staining, immunostained samples were incubated for 30 min with PBS containing Hoechst 33342. The samples were washed with PBS before examination by fluorescence microscopy. For controls, primary antibodies were substituted with pre-immune sera.

\section{Immunoelectron microscopy}

For pre-embedding immunoelectron microscopy, purified mouse spermatozoa collected from the caput and cauda epididymides of adult mice were probe-sonicated (TOMY UR-150P) at maximum power in $50 \mathrm{mM}$ Tris- $\mathrm{HCl}$ ( $\mathrm{pH}$ 8.0) on ice for $10 \mathrm{~s}$ bursts, and then centrifuged at $5000 \mathrm{~g}$ for $10 \mathrm{~min}$ to generate pellets. The pellets were fixed in PBS containing $6 \%(\mathrm{w} / \mathrm{v})$ paraformaldehyde and $0.2 \%(\mathrm{v} / \mathrm{v})$ glutaraldehyde at $4{ }^{\circ} \mathrm{C}$ for $3 \mathrm{~h}$, washed in PBS and incubated for $30 \mathrm{~min}$ in PBS containing $0.5 \%(\mathrm{w} / \mathrm{v})$ bovine serum albumin and $0.5 \%(\mathrm{w} / \mathrm{v})$ gelatin. Samples were then immunostained for $3 \mathrm{~h}$ with the anti-MS4A13-2 antibody (C-terminus), followed by incubation for $2 \mathrm{~h}$ with $10 \mathrm{~nm}$ gold particle-conjugated goat anti-rabbit IgG (GE Healthcare UK). For controls, the primary antibody was replaced by pre-immune serum. After immunostaining, samples were washed in PBS and fixed in $3 \%(\mathrm{v} / \mathrm{v})$ glutaraldehyde in $0.1 \mathrm{M}$ cacodylate buffer ( $\mathrm{pH} 7.4)$, postfixed in $1 \%(\mathrm{v} / \mathrm{v})$ osmium tetroxide, dehydrated in a graded series of ethanol and embedded in epoxy resin. Ultrathin sections $(80 \mathrm{~nm})$ cut with a diamond knife were mounted on copper grids and examined in a Hitachi $\mathrm{H}-600$ electron microscope (Tokyo, Japan) at $75 \mathrm{kV}$, after staining with $2 \%(\mathrm{w} / \mathrm{v})$ uranyl acetate and lead citrate (Sigma-Aldrich).

\section{Triton X-100 treatment of spermatozoa collected from the caput and cauda epididymides}

Spermatozoa collected from the caput and cauda epididymides of adult mice were purified by Percoll density gradient centrifugation and extracted for $1 \mathrm{~h}$ in PBS containing $1 \%$ $(\mathrm{v} / \mathrm{v})$ Triton X-100 and protease inhibitor cocktail, after which the samples were centrifuged for $3 \mathrm{~min}$ at $3300 \mathrm{~g}$ to separate extracts from undissolved pellets. To observe the ultrastructure of spermatozoa treated with Triton X-100, 1\% Triton X-100treated spermatozoa were fixed in $3 \%$ glutaraldehyde in $0.1 \mathrm{M}$ sodium cacodylate buffer ( $\mathrm{pH} 7.4$ ), postfixed in $1.3 \%$ osmium tetroxide, dehydrated in a graded ethanol series and embedded in epoxy resin. Samples were then processed for electron microscopy, as described earlier.

Both the supernatant and the pellet obtained after treatment with $1 \%$ Triton X-100 were dissolved in SDS-PAGE buffer for electrophoresis and processed for immunoblot analyses. Membranes were incubated for $2 \mathrm{~h}$ with either polyclonal antiMS4A13-2 antibody (C-terminus) diluted 1:5000, monoclonal anti-MN7 antibody diluted 1:2000, or monoclonal anti-alpha tubulin antibody (clone No. 10G10) (Wako Pure Chemical) diluted 1:1000, in blocking buffer, followed by incubation with anti-rabbit or anti-mouse IgG conjugated with HRP (BioRad) diluted 1:2000 in the same buffer. Antigen-antibody complexes were visualized using an ECL-Plus detection Kit (BioRad). 
1\% Triton X-100-treated spermatozoa collected from caput and cauda epididymides of adult mice were fixed in $4 \%(\mathrm{w} / \mathrm{v})$ paraformaldehyde in PBS at $4{ }^{\circ} \mathrm{C}$ for $1 \mathrm{~h}$, washed in PBS and then mounted on poly-L-lysine-coated glass slides for immunolabeling. Samples were processed for immunostaining and examination by fluorescence microscopy, as described earlier.

\section{Acrosome reaction in vitro}

Spermatozoa isolated from cauda epididymides of mature male mice were capacitated for $1 \mathrm{~h}$ at $37^{\circ} \mathrm{C}$ in a humidified atmosphere of $5 \%(\mathrm{v} / \mathrm{v}) \mathrm{CO}_{2}$ in air in TYH capacitation medium (modified Krebs-Ringer bicarbonate; $119.37 \mathrm{mM} \mathrm{NaCl}$, $4.78 \mathrm{mM} \mathrm{KCl}, 1.71 \mathrm{mM} \mathrm{CaCl} \cdot 2 \mathrm{H}_{2} \mathrm{O}, 1.19 \mathrm{mM} \mathrm{MgSO} \cdot 7 \mathrm{H}_{2} 0$, $1.19 \mathrm{mM} \mathrm{KH} \mathrm{PO}_{4}, 25.07 \mathrm{mM} \mathrm{NaHCO}, 5.56 \mathrm{mM}$ glucose, $0.5 \mathrm{mM}$ sodium pyruvate, $75 \mu \mathrm{g} / \mathrm{mL}$ potassium penicillin $\mathrm{G}$, $50 \mu \mathrm{g} / \mathrm{mL}$ streptomycin sulfate, $2 \mu \mathrm{g} / \mathrm{mL}$ phenol red; $\mathrm{pH} 7.2$; Toyoda et al. 1971) supplemented with BSA (4 mg/mL). To undergo the acrosome reaction, capacitated spermatozoa were treated at $37^{\circ} \mathrm{C}$ with or without (control) $10 \mu \mathrm{M}$ calcium ionophore A23187 (Sigma-Aldrich). Spermatozoa treated for $0,5,10,15,20,30$ and 60 min with calcium ionophore and for $30 \mathrm{~min}$ without calcium ionophore were fixed with $3 \%(\mathrm{w} / \mathrm{v})$ paraformaldehyde for $15 \mathrm{~min}$, washed in PBS and mounted on poly-L-lysine-coated glass slides. Spermatozoa immunostained for MS4A13-2 (C-terminus), MN7 (or PNA) and nuclei were examined by fluorescence microscopy, as described earlier. At least 200 spermatozoa treated for each time with calcium ionophore A23187 were examined for the presence or absence of PNA and change in localization of MS4A13.

Spermatozoa treated for $30 \mathrm{~min}$ with or without calcium ionophore A23187 were dissolved in SDS-PAGE buffer for electrophoresis. Samples were processed for immunoblot analysis, as described earlier.

\section{Treatment with BS3 crosslinker in acrosome-reacted spermatozoa}

BS3 (Bis (sulfosuccinimidyl) suberate, Thermo Scientific) was used to investigate whether MS4A13-2 forms hetero/homooligomers in sperm membranes. Spermatozoa treated for 30 min with calcium ionophore A23187, as described earlier, were exposed for $1 \mathrm{~h}$ at $4^{\circ} \mathrm{C}$ to PBS in the presence or absence (control) of BS3 crosslinker at a final concentration of $2 \mathrm{mM}$. The reaction was quenched by the addition of Tris- $\mathrm{HCl}(\mathrm{pH}$ 7.0) to a final concentration $20 \mathrm{mM}$ and incubated at $4{ }^{\circ} \mathrm{C}$ for $30 \mathrm{~min}$. Spermatozoa were then centrifuged at $5000 \mathrm{~g}$ for 10 min to generate pellets. The pellets were dissolved in SDSPAGE buffer for electrophoresis and processed for immunoblot analysis, as described earlier.

\section{IVF investigation}

Mature female mice were induced to ovulate by consecutive injections of $5 \mathrm{IU}$ eCG (SEROTROPIN; ASKA Animal HealthTokyo, Japan) followed $48 \mathrm{~h}$ later by $5 \mathrm{IU}$ hCG (GONATROPIN; ASKA Animal Health).
Oocytes with cumulus were collected $13-15 \mathrm{~h}$ after the injection of hCG by rupturing the ampulla of oviducts under oil in an IVF dish (Falcon Plastics, Brookings, SD, USA). For the zona pellucida-intact experiment, in which capacitated spermatozoa inseminated zona pellucida-intact oocytes with cumulus, the oocytes were transferred to another IVF dish containing TYH medium ( $\mathrm{pH} 7.2$ ) equilibrated with $5 \% \mathrm{CO}_{2}$ in air at $37^{\circ} \mathrm{C}$. For the zona pellucida-free experiment, in which spontaneous acrosome-reacted spermatozoa inseminated zona pellucida-free oocytes, oocytes were treated with $0.05 \%$ hyaluronidase in TYH medium for $10 \mathrm{~min}$ to remove cumulus cells, and then the cumulus-free oocytes were washed twice in TYH medium. The zona pellucida was removed from these oocytes by brief treatment with low- $\mathrm{pH}$ ( $\mathrm{pH} 2.5)$ TYH medium. Zona pellucida-free oocytes were transferred to an IVF dish that contained TYH medium $(\mathrm{pH} 7.2)$ equilibrated with $5 \%$ $\mathrm{CO}_{2}$ in air, and then incubated for $1 \mathrm{~h}$ at $37^{\circ} \mathrm{C}$ for recovery before use (Toshimori et al. 1998).

Spermatozoa collected from the cauda epididymis of mature male mice, as described earlier, were allowed to disperse into $400 \mu \mathrm{L} \mathrm{TYH}$ medium and capacitated for $1 \mathrm{~h}$ at $37^{\circ} \mathrm{C}$. The capacitated spermatozoa were diluted to a final concentration of $4 \times 10^{4} \mathrm{sperm} / \mathrm{mL}$ in TYH medium with or without antiserum $(100 \mu \mathrm{g} / \mathrm{mL})$, anti-MS4A13-2 antibody (C-terminus; $100 \mu \mathrm{g} /$ $\mathrm{mL}$ ) or anti-MS4A13-2 antibody (extracellular region; 25, 50, $100 \mu \mathrm{g} / \mathrm{mL}$ ), and preincubated for $30 \mathrm{~min}$ before insemination.

The zona pellucida-intact and -free oocytes were then added to the spermatozoa in TYH medium containing antibodies. The formation of two cells was determined by phase-contrast microscopy (Leica DM RXA) $24 \mathrm{~h}$ after insemination.

\section{Results}

\section{Isolation of Ms4a13-2 by PCR-selected subtraction analysis}

To identify genes developmentally upregulated in the shrew testis, transcripts derived from the testes of 10-day-old and 12-week-old animals were examined by PCR-selected subtraction analysis, which resulted in isolation of 174 DNA fragments (data not shown, currently undergoing analysis). Sequence data from these clones were subjected to a homology searching of the NCBI database and an unpublished Suncus genome resource (currently undergoing preparation for publication) using the program, BLAST. One of the genes was highly homologous to two mouse transcripts: membrane-spanning 4-domains, subfamily A, member 13, transcript variant 1 (Ms4a13-1; NCBI Reference Sequence, NM_198224) and Ms4a13 transcript variant 2 (Ms4a13-2; NCBI Reference Sequence, NM_001347435), and to a Suncus transcript: Ms4A13 (Suncus genome resource, reference number R57005, currently under analysis). A BLAST search against the $\mathrm{NCBI}$ mouse genomic database revealed that Ms4a13 was composed of 8 exons (Fig. 1A) and located on mouse chromosome 19A, and that exon 7 of Ms4a13-2 mRNA was removed by splicing (Fig. 1B). The cDNAs of 
A
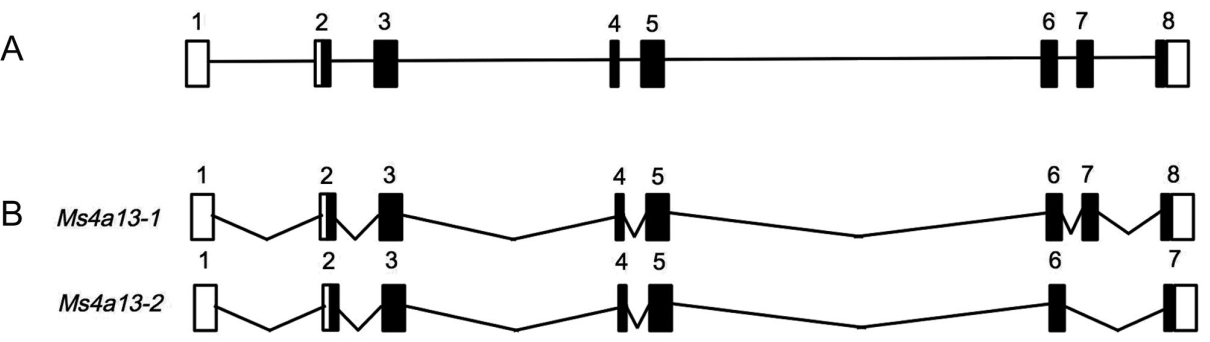

C
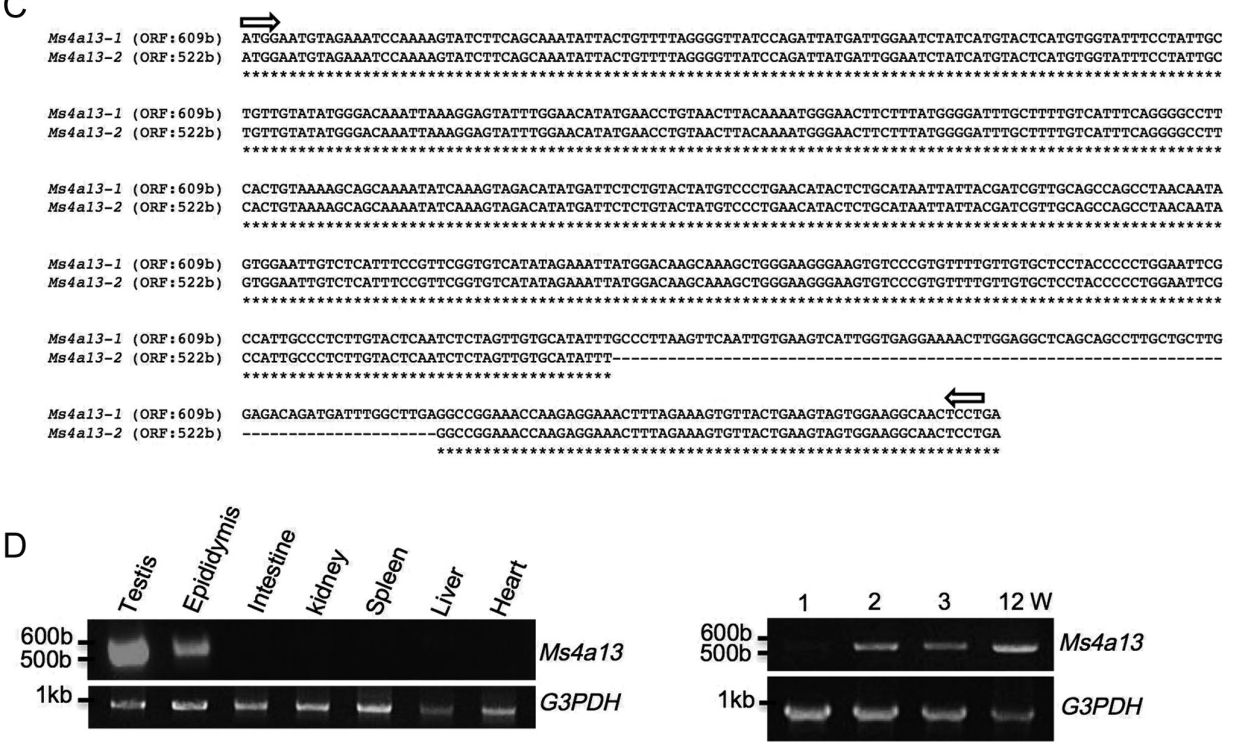

$\mathrm{E}$

ATGGAATGTAGAAATCCAAAAGTATCTTCAGCAAATATTACTGTTTTAGGGGTTATCCAGATTATGATTGGAATCTATCATGTACTCATG \begin{tabular}{llllllllllllllllllllllllllllll}
$M$ & $E$ & $C$ & $R$ & $N$ & $P$ & $K$ & $V$ & $S$ & $S$ & $A$ & $N$ & $I$ & $T$ & $V$ & $L$ & $G$ & $V$ & $I$ & 0 & $I$ & $M$ & $I$ & $G$ & $I$ & $Y$ & $H$ & $V$ & $L$ & $M$ \\
\hline
\end{tabular} TGGTATTTCCTATTGCTGTTGTATATGGGACAAATTAAAGGAGTATTTGGAACATATGAACCTGTAACTTACAAAATGGGAACTTCTTTA $\begin{array}{llllllllllllllllllllllllllllll}\text { W } & Y & F & L & L & L & L & Y & M & G & Q & I & K & G & V & F & G & T & Y & E & P & V & T & Y & K & M & G & T & S & L\end{array}$ TGGGGATTTGCTTTTGTCATTTCAGGGGCCTTCACTGTAAAAGCAGCAAAATATCAAAGTAGACATATGATTCTCTGTACTATGTCCCTG $\begin{array}{llllllllllllllllllllllllllllll}\text { W } & G & F & A & F & V & I & S & G & A & F & T & V & K & A & A & K & Y & Q & S & R & H & M & I & L & C & \underline{T} & M & S & L\end{array}$ AACATACTCTGCATAATTATTACGATCGTTGCAGCCAGCCTAACAATAGTGGAATTGTCTCATTTCCGTTCGGTGTCATATAGAAATTAT

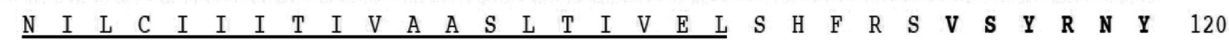
GGACAAGCAAAGCTGGGAAGGGAAGTGTCCCGTGTTTTGTTGTGCTCCTACCCCCTGGAATTCGCCATTGCCCTCTTGTACTCAATCTCT

$\begin{array}{lllllllllllllllllllllllllllllll}G & \boldsymbol{Q} & \mathbf{A} & \mathbf{K} & \mathrm{L} & \mathbf{G} & \mathbf{R} & \mathrm{E} & \mathrm{V} & \mathrm{S} & \mathrm{R} & \mathrm{V} & \mathrm{L} & \mathrm{L} & \mathrm{C} & \mathrm{S} & \mathrm{Y} & \mathrm{P} & \mathrm{L} & \mathrm{E} & \mathrm{F} & \mathrm{A} & \mathrm{I} & \mathrm{A} & \mathrm{L} & \mathrm{L} & \mathrm{Y} & \mathrm{S} & \mathrm{I} & \mathrm{S} & 150\end{array}$ AGTTGTGCATATTTGGCCGGAAACCAAGAGGAAACTTTAGAAAGTGTTACTGAAGTAGTGGAAGGCAACTCCTGA

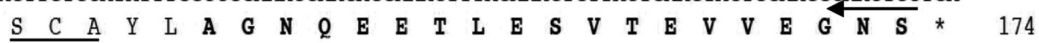

Figure 1 (A) Schematic representation of the mouse Ms4a13 gene. Numbered boxes indicate exons and lines connecting the exons represent introns. The Ms4a13 gene is composed of 8 exons. (B) Schematic representation of partial Ms4a13-1 and Ms4a13-2 mRNAs. The Ms4a13-1 and Ms4a13-2 mRNAs are composed of 8 and 7 exons, respectively, because exon 7 of Ms4a13-2 is removed by splicing. (C) The cDNA coding sequences of mouse Ms4a13-1 (accession number NM_198224) and Ms4a13-2 (accession no. NM_001347435). The cDNAs of mouse Ms4a13-1 and Ms4a13-2 contain open-reading frames (ORFs) of 609 and 522 nucleotides, encoding proteins of 203 (accession no. NP_937867) and 174 (accession no. NP_001334364) amino acid residues, respectively. Deletions are indicated by dashes. Asterisks denote shared identical nucleotides between the two cDNAs. The DNA fragment located between the two white arrows, which is shared by Ms4a13-1 and Ms4a13-2, was amplified by RT-PCR in Fig. 1D. (D) Left panel, RT-PCR analysis to examine the expression levels of Ms4a13-1 and Ms4a13-2 in various organs of adult mouse. Ms4a13-2 (523 bp) is highly expressed in testis and epididymis, and detected at much lower levels in kidney, spleen, liver and heart; however, Ms4a13-1 (610 bp) was not detected in any organ examined. Right panel, RT-PCR analysis of the expression of Ms4a13-2 in testis of 1-, 2-, 3- and 12-week-old mice. A PCR product of 523 bp was first detected at 2-week postpartum and continued to be observed into adulthood. G3pdh was amplified as a control. (E) The cDNA coding sequence and predicted amino acid sequence of mouse MS4A13-2. The termination codon, TGA, is indicated by an asterisk. MS4A13-2 contains transmembrane regions at AAs 14-36, 56-77, 87-109 and 131-153 (underlined). Two polyclonal antibodies were raised against the synthetic peptides, VSYRNYGQAKLGR and AGNQEETLESVTEVVEGNS, corresponding to AAs 115-127 (putative extracellular region) and 156-174 (C-terminus) of MS4A13-2 (boldface type), respectively. An Ms4a13-2 DNA fragment of $300 \mathrm{bp}$ in length, located between the two arrows, was amplified by PCR and used for transfection into COS7 cells. 
Ms4a13-1 and Ms4a13-2 contain ORFs of 609 and 522 nucleotides, encoding proteins of 203 (NCBI Reference Sequence, NP_937867) and 174 (NCBI Reference Sequence, NP_001334364) AA residues, respectively. The deduced nucleotide sequences of the mouse Ms4a13-1 and Ms4a13-2 ORFs are shown in Fig. 1C. The predicted molecular masses and isoelectric points of mouse MS4A13-1 and MS4A13-2 are 22,783 Da and 19,345 Da and 9.11 and 8.26, respectively. A BLAST search against the Suncus genome resource revealed that the Suncus Ms4a13 cDNA contains an ORF of 519 nucleotides, encoding proteins of 173 AA residues (Supplementary Fig. 1, see section on supplementary data given at the end of this article).

We examined the expression of Ms4a13-1 and Ms4a13-2 mRNAs in various organs of adult mice by RT-PCR. A 523-bp Ms4a13-2 RT-PCR product was strongly expressed in the testis and epididymis, and was detected at much lower levels in the kidney, spleen, liver and heart. A 610-bp Ms4a13-1 RT-PCR product was undetectable in all organs examined (Fig. 1D, left panel). We next performed RT-PCR to study the developmental expression of Ms4a13-2 mRNA in testis of 1-, 2-, 3- and 12 -week-old mice and found that it was first detected at 2 weeks postnatally and continued to be expressed into adulthood (Fig. 1D, right panel).

SOSUI (http://harrier.nagahama-i-bio.ac.jp/sosui/ sosui_submit.html) predicted that AA residues 14-36, 56-77, 87-109 and 131-153 of mouse MS4A13-2 form transmembrane regions (Fig. 1E), indicating that MS4A13-2 has four potential membrane-spanning domains, with $\mathrm{N}$ - and C-terminal cytoplasmic domains. In contrast, analyses with SMART (http://smart.emblheidelberg.de), TMHMM (http://www.cbs.dtu.dk/ services/TMHMM/) and Ensembl (http://www.ensembl. org/index.html) suggested that mouse MS4A13-2 has three potential transmembrane regions with an $\mathrm{N}$-terminal cytoplasmic domain and an extracellular C-terminus, and that AAs 15-117 of mouse MS4A13-2 comprise a CD20 domain.

\section{Specificity of the anti-MS4A13-2 antibodies}

To examine the expression and localization of MS4A13-2 protein in the mouse testis, epididymis and spermatozoa, two polyclonal antibodies were raised against two synthetic peptides (VSYRNYGQAKLGR and AGNQEETLESVTEVVEGNS) corresponding to AAs 115-127 (putative extracellular region) and 156-174 (C-terminus) of mouse MS4A13-2, respectively (Fig. 1E).

Specificity of the affinity-purified anti-MS4A13-2 antibodies was first examined by immunoblot of RFPtagged MS4A13-2 (AAs 75-174) expressed in COS7 cells. As shown in Fig. 2A, both the anti-MS4A13-2 (extracellular region, Fig. 2A, third panel from the right; and C-terminus, Fig. $2 \mathrm{~A}$, second panel from the right) antibodies and the anti-RFP antibody (Fig. 2A, right panel) recognized a protein migrating at approximately $38 \mathrm{kDa}$, which was not detected in control samples (untransfected cells).

Next, COS7 cells transfected with RFP-tagged MS4A13-2 were examined by fluorescence microscopy after labeling with each of the two anti-MS4A13-2 antibodies (green color). The RFP-tagged MS4A13-2 (AAs 75-174) detected by the anti-MS4A13-2 antibodies (extracellular region, Fig. 2B, upper panel; and C-terminus, Fig. 2B, lower panel) appeared as small aggregates in the cytoplasm. The fluorescence representing the anti-MS4A13-2 antibodies overlapped with that representing RFP. Replacement of the antiMS4A13-2 antibodies with pre-immune sera produced little or no green labeling in the cells (Fig. 2B, right panel). These results demonstrate that both the anti-MS4A13-2 antibodies specifically recognize RFP-tagged MS4A13-2 expressed in COS7 cells. The two anti-MS4A13-2 antibodies were used for subsequent experiments.

\section{Detection of MS4A13-2 in mouse testis}

We next performed immunoblot analysis to investigate the expression of MS4A13-2 in mouse testis. On blots containing proteins extracted in RIPA buffer and immunoprecipitated with the anti-MS4A13-2 antibody (C-terminus) from mouse seminiferous tubule, the two anti-MS4A13-2 antibodies (extracellular region, Fig. 3A, lane 1 in right panel; and C-terminus, Fig. 3A, lane 2 in right panel) recognized a protein migrating at approximately $19 \mathrm{kDa}$, close to the theoretical molecular weight $(19.3 \mathrm{kDa})$ calculated from the MS4A13-2 AA sequence, deduced from the cDNA sequence. The 19-kDa protein was not detected when control pre-immune serum was used instead of the antiMS4A13-2 antibody (C-terminus; Fig. 3A, lane 3 in right panel). These data indicate that the antibodies, which were raised against two synthetic MS4A13-2 peptides, specifically recognize MS4A13-2 protein expressed in the mouse testis.

\section{Immunolocalization of MS4A13-2 protein in the mouse testis}

We used fluorescence microscopy of frozen sections of adult mouse testis stained with anti-MS4A13-2 antibodies (extracellular region and C-terminus) to determine the cell types expressing MS4A13-2 protein. In cross sections of stages I-XII of the cycle of the mouse seminiferous epithelium, MS4A13-2 was detected along the periphery of nuclei of round (Fig. 3B, upper panel) and elongating (Fig. 3B, lower left panel) spermatids, while spermatogonia, spermatocytes, Sertoli cells and interstitial cells were devoid of the signal (Fig. 3B, upper panel). No specific staining was visible in controls stained with pre-immune serum (Fig. 3B, lower right panel). No distinct difference in immunolabeling was discernible 
A

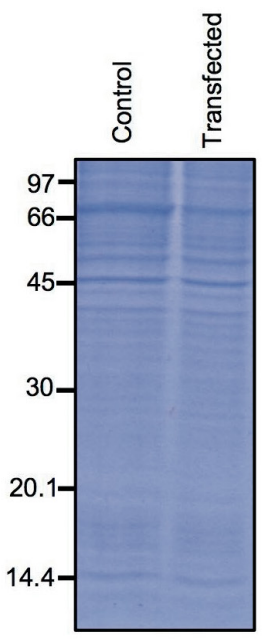

B
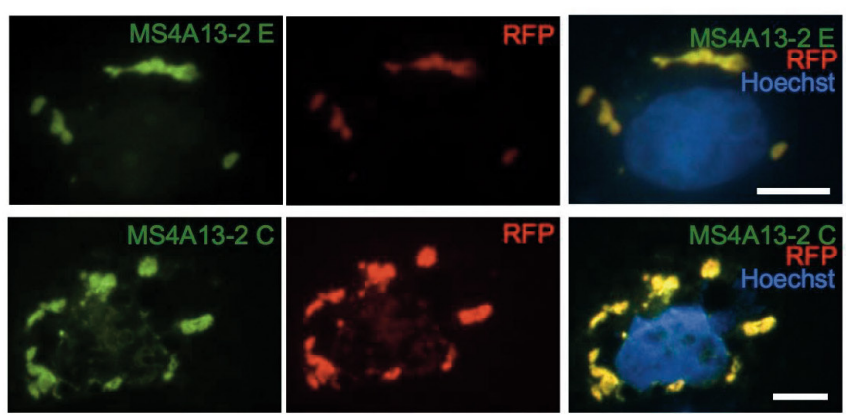

between the two anti-MS4A13-2 antibodies against the extracellular region (not shown) and C-terminus.

To determine the subcellular distribution of MS4A13-2 protein in mouse spermatids, fluorescence microscopy was carried out by double-staining mouse testis with antiMS4A13-2 antibody (C-terminus) and MN7 monoclonal antibody. At higher magnification, MS4A13-2 was initially observed at acrosomal vesicles labeled by MN7 antibody (a marker protein for the acrosome, but not for the equatorial region) in step 3 round spermatid at stages II-III (Fig. 3C, step 3). As the acrosomal vesicle extended, MS4A13-2 appeared to cover the outer surface of the acrosomal vesicle (Fig. 3C, step 5), and to gradually extend backward (Fig. 3C, steps 7 and 8). In the elongating spermatid, MS4A13-2 was detected mainly along the posterior part of nuclei, separate from the MN7 signal (Fig. 3C, elongating spermatid).

\section{Detection of MS4A13-2 in mouse spermatozoa}

We next examined whether MS4A13-2 was expressed in mouse spermatozoa. Spermatozoa derived from the caput and cauda of mouse epididymides were purified by Percoll density gradient centrifugation and subjected

Reproduction (2017) 154 843-857
Figure 2 (A) Immunoblot analysis demonstrating the specificity of the antiMS4A13-2 antibodies. Proteins extracted from COS7 cells expressing RFP-tagged truncated MS4A13-2 (transfected), as well as nontransfected COS7 cells (control), were separated by SDS-PAGE and either stained with Coomassie brilliant blue (left panel) or subjected to immunoblot analysis using anti-MS4A13-2 (extracellular region, Fig. 2A, third panel from the right), anti-MS4A13-2

(C-terminus, Fig. 2A, second panel from the right) or anti-RFP (right panel) antibodies. A protein migrating at approximately $38 \mathrm{kDa}$ was detected by the three antibodies in transfected cells, and not in non-transfected cells. The molecular masses $(\mathrm{kDa})$ of the standard proteins are shown on the left. (B)

Fluorescence microscopy demonstrating the specificity of the anti-MS4A13-2 antibodies. COS7 cells transfected with the C-terminus of MS4A13-2-RFP were examined by immunofluorescence microscopy. The green signals from the two anti-MS4A13-2

antibodies (E, extracellular region, upper panel; and C, C-terminus, lower panel; each leftmost panel) and the red signal from RFP (panels second from the left) were merged (panels third from the left, yellow color). Nuclear DNA was stained using Hoechst 33342 (blue color). In transfected COS7 cells, truncated MS4A13-2-RFP appears as small aggregates in the cytoplasm. Little or no green labeling was visible in control samples stained with pre-immune sera (rightmost panels).

Scale bars, $10 \mu \mathrm{m}$.

to SDS-PAGE and immunoblotting. We found that the two anti-MS4A13-2 antibodies (extracellular region, Fig. 4A; and C-terminus, not shown) recognized a single protein migrating at $19 \mathrm{kDa}$ in spermatozoa derived from both caput and cauda of epididymides, indicating that MS4A13-2 is expressed in spermatozoa.

To investigate the subcellular distribution of MS4A13-2 in mouse spermatozoa in the epididymis, membrane (mainly containing plasma membrane), head (without membrane fraction) and flagella (without membrane fraction) fractions of spermatozoa were subjected to immunoblot analysis using the anti-MS4A13-2 antibody (C-terminus). MS4A13-2 was detected strongly in the head fraction, suggesting that MS4A13-2 is primarily expressed in the sperm head without the plasma membrane (Fig. 4B).

To examine the localization of MS4A13-2 in mouse spermatozoa, we performed fluorescence immunocytochemistry. In both the caput (not shown) and the cauda of adult mouse epididymides, MS4A13-2 was detected in sperm, but not in epididymal epithelial cells (Fig. 4C, upper panel). At high magnification of sperm from both caput (not shown) and cauda epididymides, MS4A13-2 was visible along the periphery of nuclei in the sperm heads (Fig. 4C, lower left panel). No distinct 
A
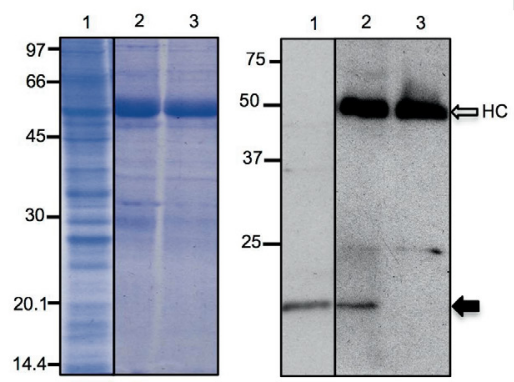

C
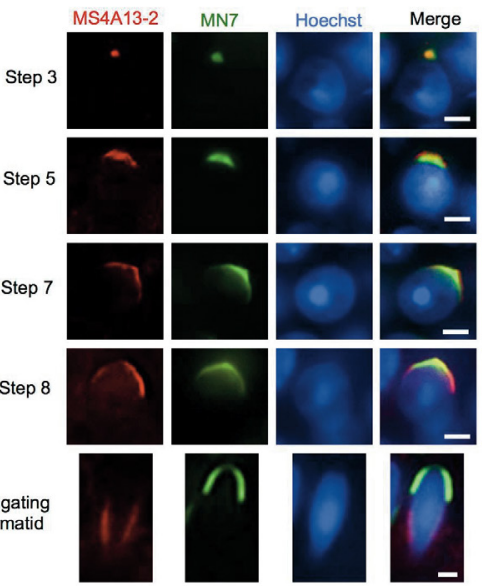

B
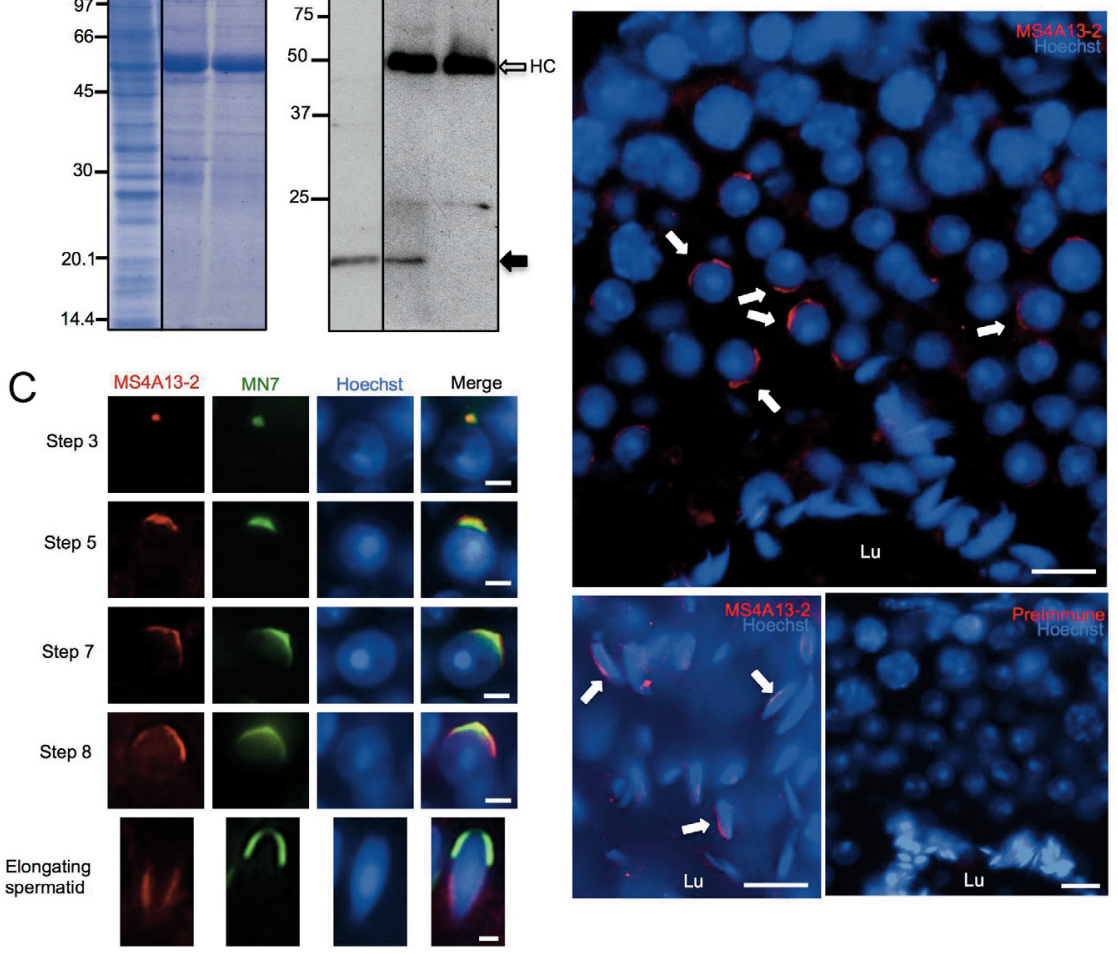

Figure 3 (A) Immunoblot analyses of proteins extracted in RIPA buffer and immunoprecipitated from seminiferous tubules using the two anti-MS4A13-2 antibodies. Clarified supernatants in RIPA buffer from seminiferous tubules of adult mouse testes were immunoprecipitated using either the anti-MS4A13-2 antibody (C-terminus) or pre-immune serum. Proteins extracted in RIPA buffer (lane 1) and immunoprecipitated (lane 2 and 3) were separated by SDS-PAGE, and stained with Coomassie brilliant blue (left panel) or subjected to immunoblot analyses using the anti-MS4A13-2 antibodies (extracellular region, lane 1 in right panel; and C-terminus, lanes 2 and 3 in right panel). The anti-MS4A13-2 antibodies recognized a protein migrating at approximately $19 \mathrm{kDa}$ (black arrow) in samples extracted in RIPA buffer (lane 1 in right panel) and immunoprecipitated (lane 2 in right panel). No band was detected when control pre-immune serum was used instead of the anti-MS4A13-2 antibody (lane 3 in right panel). White arrow, heavy chains (HC) of IgG. Molecular masses $(\mathrm{kDa})$ of standard proteins are shown on the left. (B) Immunohistochemical localization of MS4A13-2 in the seminiferous tubules of adult mouse testis. Frozen sections of adult mouse testis stained with the anti-MS4A13-2 antibody (C-terminus; red) were counter-stained with Hoechst 33342 to visualize nuclear DNA (blue). Immunofluorescence representing MS4A13-2 was detected along the periphery of round (step 8 spermatid in stage VIII, upper panel) and elongating (lower left panel) spermatid nuclei (arrows), and was not detected in spermatogonia, spermatocytes, somatic Sertoli cells or testis interstitial cells (upper panel). No specific staining was observed using the pre-immune serum control (lower right panel). Lu, lumen of the seminiferous tubules. Scale bars, $10 \mu \mathrm{m}$. (C) Subcellular distribution of MS4A13-2 protein in mouse spermatids. Frozen sections of adult mouse testis were double-stained with anti-MS4A13-2 antibody (C-terminus; red) and anti-MN7 monoclonal antibody (green; marker of the acrosome). Nuclear DNA was stained using Hoechst 33342 (blue). Three color images are superimposed in right panels (merge). MS4A13-2 is visible as small round area of immunofluorescence in the MN7 positive acrosomal vesicle in a step 3 round spermatid at stage II-III (step 3). As the acrosomal vesicle extends, MS4A13-2 immunolabeling covers the outer surface of the acrosomal vesicle (step 5), gradually extending backward (step 7 and step 8). In the elongating spermatid, MS4A13-2 is detected primarily along the posterior part of nuclei, separate from the MN7 signal (elongating spermatid). Scale bars, $3 \mu \mathrm{m}$ in steps $3-8$, and $1 \mu \mathrm{m}$ in elongating spermatid.

immunosignal was observed in controls labeled with pre-immune serum (Fig. 4C, lower right panel). When spermatozoa isolated from caput and cauda mouse epididymides were immunostained, MS4A13-2 was strongly detected in the equatorial region of sperm heads marked by FITC-PNA (Fig. 4D), and weakly in the principal piece of sperm flagella (not shown).

To determine the localization of MS4A13-2 in sperm heads in detail, mouse caput and cauda epididymis spermatozoa treated with sonication to almost remove plasma membranes were evaluated by pre-embedding immunoelectron microscopy using the anti-MS4A13-2 antibody (C-terminus) and 10-nm gold-conjugated secondary antibody. The majority of MS4A13-2 was associated with naked outer acrosomal membrane at the equatorial region (Fig. 4E, left panel). The outer acrosomal membrane at the acrosomal cap exhibited very little labeling, even when the outer acrosomal membrane was exposed by removal of the majority of the plasma membrane by sonication. Little or no labeling was observed in control samples stained with pre-immune serum (Fig. 4E, right panel). No distinct difference in immunolabeling was discernible between caput (not shown) and cauda epididymis spermatozoa. 


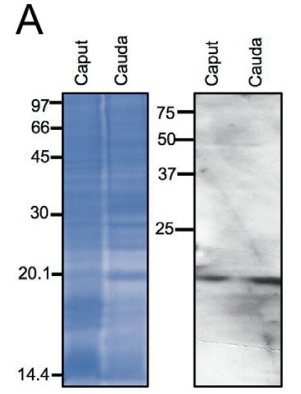

$\mathrm{E}$

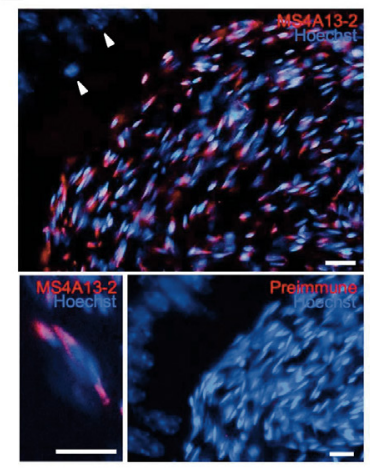

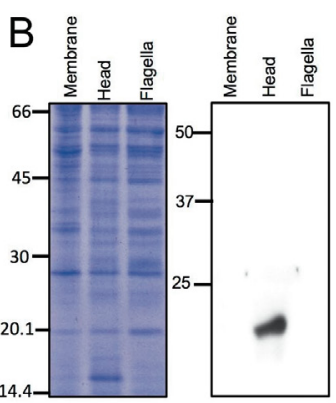

D

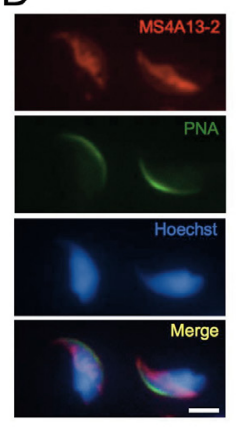

C

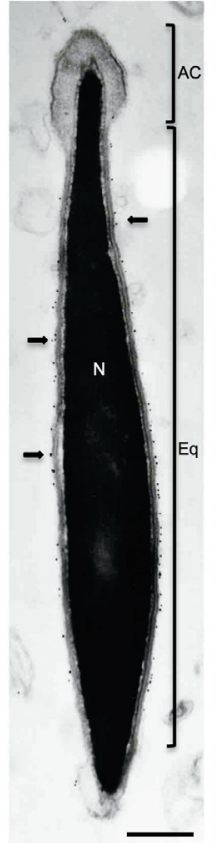

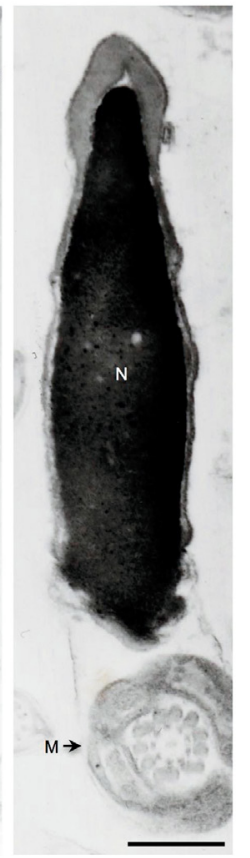

Figure 4 (A) Immunoblot analysis of MS4A13-2 in spermatozoa. Proteins from spermatozoa purified from caput and cauda epididymides were separated by SDS-PAGE, and either stained with Coomassie brilliant blue (left panel) or transferred to a filter for immunoblot analysis with anti-MS4A13-2 antibody (extracellular region; right panel). A band migrating at 19 kDa was detected in both samples using the anti-MS4A13-2 antibody. Molecular masses (kDa) of standard proteins are shown on the left. (B) Subcellular distribution of MS4A13-2 in mouse spermatozoa from epididymides. The membrane (mainly containing plasma membrane), head (except membrane fraction) and flagella (except membrane fraction) fractions of spermatozoa were separated by SDS-PAGE, and either stained with Coomassie brilliant blue (left panel) or subjected to immunoblot analysis using the anti-MS4A13-2 antibody (C-terminus; right panel). MS4A13-2 is visible strongly in the head fraction of spermatozoa. Molecular masses $(\mathrm{kDa})$ of standard proteins are shown to the left. (C) Immunohistochemical localization of MS4A13-2 in mouse epididymides. Frozen sections of cauda of adult mouse epididymides stained with anti-MS4A13-2 antibody (C-terminus; red) were counterstained with Hoechst 33342 to visualize nuclear DNA (blue). MS4A13-2 is associated with sperm and not found in epididymal epithelial cells (arrowheads in upper panel). At high magnification in sperm from cauda epididymis, MS4A13-2 was visible along the periphery of nuclei in the sperm heads (lower left panel). Staining with pre-immune serum produced negative results (lower right panel). Scale bars, $10 \mu \mathrm{m}$. (D) Spermatozoa stained with the anti-MS4A13-2 antibody (C-terminus; red), followed by incubation with PNA-FITC (green) and Hoechst counterstaining (blue). Merged images are shown in the bottom panel. At high magnification, MS4A13-2 immunolabeling is visible in the equatorial region of sperm heads. Scale bar, $3 \mu \mathrm{m}$. (E) Pre-embedding immunoelectron microscopy of MS4A13-2 in mouse spermatozoa. Purified spermatozoa from cauda epididymides were sonicated, fixed and processed for immunolabeling using the anti-MS4A13-2 antibody (C-terminus) and 10-nm gold-conjugated goat anti-rabbit IgG. Plasma membrane was mostly removed by sonication. MS4A13-2 is primarily visible at the naked outer acrosomal membrane (arrows) at the equatorial region (Eq), with no distinct immunolabeling on the exposed outer acrosomal membrane at the acrosomal cap (AC) (left panel). Little or no labeling is visible in control samples stained with pre-immune serum (right panel). $\mathrm{M}$, middle piece. $\mathrm{N}$, nucleus. Scale bars, $0.5 \mu \mathrm{m}$.

\section{Biochemical examination of caput and cauda epididymis spermatozoa}

Morphologically, there was no difference in the subcellular localization of MS4A13-2 between caput and cauda epididymis spermatozoa. In order to biochemically examine differences between spermatozoa from caput and cauda epididymides, we performed $1 \%$ Triton $\mathrm{X}-100$ extraction for $1 \mathrm{~h}$ to remove some of the sperm membranes. By electron microscopy, the removal of the plasma membranes, some of the inner and outer acrosomal membranes, and a small proportion of other organelles from both caput and cauda epididymis spermatozoa were observed, as a result of treatment with Triton X-100 (Fig. 5A). The inner and outer acrosomal membranes of caput epididymis spermatozoa (Fig. 5A, left panel) were more extensively removed after Triton X-100 treatment than those of cauda epididymis spermatozoa (Fig. 5A, right panel). By immunoblotting and immunolabeling analyses, we determined that a substantial fraction of MS4A13-2 was released from caput epididymis spermatozoa by $1 \%$ Triton X-100 treatment for $1 \mathrm{~h}$, while only half of the protein was extracted from cauda epididymis spermatozoa by the same treatment (Fig. 5B, third panel from the bottom, and 5C). Detection of an MN7 (a component of the acrosome) in supernatants of both caput and cauda 
A

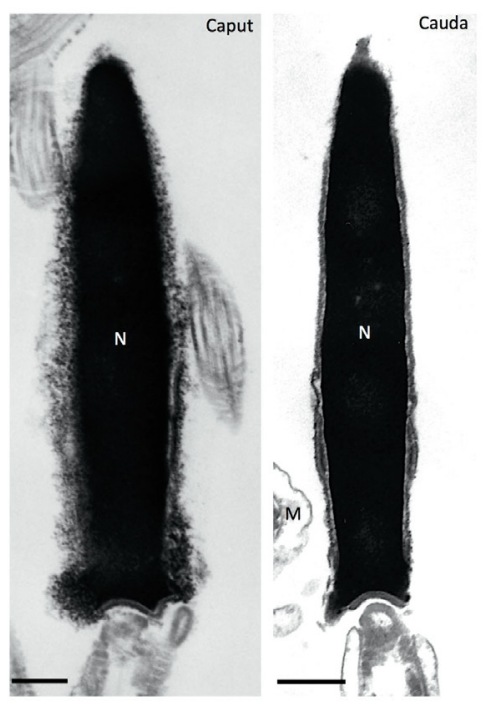

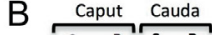

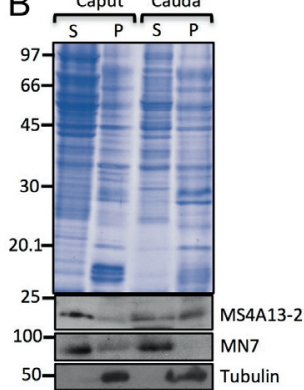

C Caput

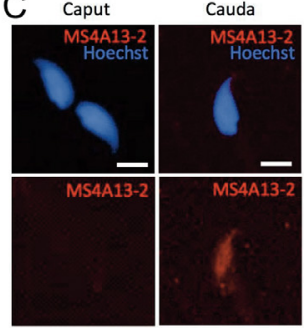

Figure 5 (A) Electron microscopy of mouse spermatozoa extracted with Triton X-100. Caput (left panel) and cauda (right panel) epididymis spermatozoa were treated for $1 \mathrm{~h}$ with $1 \%$ Triton X-100, fixed, embedded in epoxy resin and ultrathin sections examined by electron microscopy. Triton X-100 treatment removed the plasma membranes, some of the inner and outer acrosomal membranes, and a small proportion of other organelles from both caput and cauda epididymis spermatozoa. The inner and outer acrosomal membranes of caput epididymis spermatozoa were more extensively removed by Triton X-100 treatment than those of the cauda epididymis spermatozoa. $M$, middle piece. $N$, nucleus. Scale bars, $0.3 \mu \mathrm{m}$. (B) Immunoblot analyses of MS4A13-2 in mouse spermatozoa extracted using Triton X-100. Proteins in both extracts and pellets were separated by SDS-PAGE, and either stained with Coomassie brilliant blue (upper panel) or transferred to a membrane for immunoblot analysis with anti-MS4A13-2 antibody (C-terminus; third panel from the bottom) or monoclonal anti-MN7 antibody (second panel from the bottom), or monoclonal anti-alpha tubulin antibody (bottom panel). MS4A13-2 protein migrating at $19 \mathrm{kDa}$ was visible primarily in the supernatant $(S)$ from caput epididymis spermatozoa, while protein is distributed equally in both the supernatant and the pellet (P) from cauda epididymis spermatozoa. MN7 protein, migrating at $90 \mathrm{kDa}$, was detected primarily in the supernatants of caput and cauda epididymis spermatozoa, and alpha tubulin protein, migrating at $50 \mathrm{kDa}$, was detected in the pellets of caput and cauda epididymis spermatozoa. Molecular masses (kDa) of standard proteins are shown on the left. (C) Immunocytochemical localization of MS4A13-2 in mouse spermatozoa extracted with Triton X-100. Caput (left panels) and cauda (right panels) epididymis spermatozoa were treated for $1 \mathrm{~h}$ with $1 \%$ Triton X-100, fixed and immunostained with anti-MS4A13-2 antibody (C-terminus), followed by incubation with Cy3-conjugated goat anti-rabbit IgG (red). Immunostained samples were counterstained with Hoechst 33342 to visualize nuclear DNA (blue). Merged immunofluorescence images for MS4A13-2 and Hoechst 33342 are shown in upper panels. The MS4A13-2 was detected in cauda epididymis spermatozoa, whereas it was not detected in caput epididymis spermatozoa. Scale bars, $3 \mu \mathrm{m}$.

epididymis spermatozoa (Fig. 5B, second panel from the bottom) and of tubulins (components of the axoneme) in pellets of both caput and cauda epididymis spermatozoa by the same treatment (Fig. 5B, bottom panel) indicated accurate separation of supernatants and pellets from caput and cauda epididymis spermatozoa. These data suggest that the membranes of sperm heads become resistant to biochemical processing during epididymal maturation, resulting in more MS4A13-2 remaining in the outer acrosome membrane of spermatozoa in cauda epididymis after $1 \%$ Triton X-100 treatment.

\section{Alterations in MS4A13-2 after the acrosome reaction}

We examined whether localization of MS4A13-2 altered after the acrosome reaction. Capacitated spermatozoa were incubated for $30 \mathrm{~min}$ in the presence or absence (control) of the calcium ionophore A23187 $(10 \mu \mathrm{M})$. The acrosome reaction of spermatozoa was monitored by staining with the monoclonal anti-MN7 antibody and anti-mouse IgG conjugated with FITC. We observed that immunolabeling for MS4A13-2 extended to the postacrosomal region and acrosomal cap of sperm heads after the acrosome reaction (Fig. 6A, lower panel), whereas MS4A13-2 was limited to the equatorial region in fresh (Fig. 6A, upper panel) or capacitated (Fig. 6A, middle panel) spermatozoa.

We next examined when MS4A13-2 extended to the postacrosomal region and acrosomal cap of sperm heads during the acrosome reaction. Capacitated spermatozoa were incubated for $0,5,10,15,20,30$ and $60 \mathrm{~min}$ in the presence of the calcium ionophore A23187 $(10 \mu \mathrm{M})$ (Supplementary Fig. 2). The acrosome reaction of spermatozoa was monitored by FITCPNA. We found that the proportion of spermatozoa, in which PNA disappeared $(P<0.05)$ and localization of MS4A13-2 was diffused $(P<0.05)$, increased significantly between 15 and $20 \mathrm{~min}$ after the addition of calcium ionophore, and that for all the spermatozoa in which the localization of MS4A13-2 was diffused, PNA had disappeared. These data suggest that MS4A13-2 extended to the postacrosomal region and acrosomal cap of sperm heads within a maximum of $5 \mathrm{~min}$ of the disappearance of PNA.

To investigate whether the molecular size of MS4A13-2 changed before and after the acrosome reaction, spermatozoa treated for $30 \mathrm{~min}$ with or without calcium ionophore A23187 were processed for immunoblot analysis (Fig. 6B). We found that the antiMS4A13-2 antibody (extracellular region) recognized a single protein migrating at $19 \mathrm{kDa}$ in both capacitated and acrosome-reacted spermatozoa.

\section{BS3 crosslinker analysis of acrosome- reacted spermatozoa}

BS3 is a cell-surface crosslinker used to investigate the formation of protein complexes, such as dimers and tetramers. We investigated the effect of BS3 treatment on the migration of MS4A13-2 by immunoblotting. 

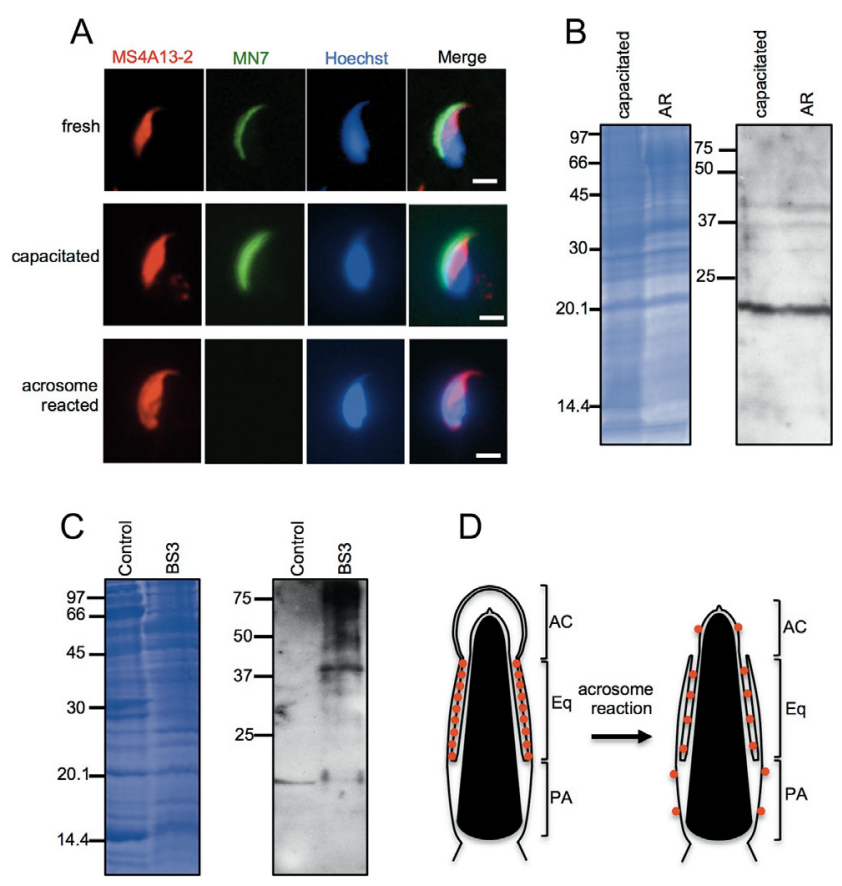

Figure 6 (A) Fluorescence microscopy of MS4A13-2 in acrosomereacted spermatozoa. The acrosome reaction of spermatozoa was monitored by staining with the monoclonal anti-MN7 antibody and anti-mouse IgG conjugated with FITC (green). Immunostained samples were counter-stained with Hoechst 33342 to visualize nuclear DNA (blue). Immunolabeling of MS4A13-2 (red) extended to the postacrosomal region and acrosomal cap of sperm heads after the acrosome reaction (lower panel), whereas in fresh (upper panel) and capacitated (middle panel) spermatozoa, MS4A13-2 was limited to the equatorial region. Scale bars, $3 \mu \mathrm{m}$. (B) Immunoblot analysis of MS4A13-2 in spermatozoa before (capacitated) and after (AR) the acrosome reaction. Spermatozoa treated with or without calcium ionophore were separated by SDS-PAGE, and either stained with Coomassie brilliant blue (left panel) or transferred to a filter for immunoblot analysis with the anti-MS4A13-2 antibody (extracellular region; right panel). A band migrating at $19 \mathrm{kDa}$ was detected in both samples. Molecular masses $(\mathrm{kDa})$ of standard proteins are shown on the left. (C) Immunoblot analysis of MS4A13-2 in non-treated (control) or BS3-treated (BS3) acrosome-reacted spermatozoa. MS4A13-2 was detected at $19 \mathrm{kDa}$ in the absence of BS3, whereas it migrates at $19 \mathrm{kDa}, 40 \mathrm{kDa}$ and the bands larger than $40 \mathrm{kDa}$ in the presence of BS3. Molecular masses $(\mathrm{kDa})$ of standard proteins are shown on the left. (D) Schematic diagrams showing the estimated translocation of MS4A13-2 (red dots) during the acrosome reaction. MS4A13-2 is initially localized on the outer acrosomal membrane of the equatorial region (Eq) (left diagram). After the acrosome reaction, it translocated to the exposed to the postacrosomal region (PA) and the acrosomal cap (AC) (right diagram).

Spermatozoa with outer acrosomal membranes exposed by treatment with calcium ionophore were treated with or without (control) BS3 crosslinker, and examined by immunoblot analysis. As shown in Fig. 6C, in the absence of BS3, MS4A13-2 was detected at $19 \mathrm{kDa}$ (monomer); however, in the presence of BS3, it migrated at $19 \mathrm{kDa}$ (monomer), $40 \mathrm{kDa}$ and the bands larger than $40 \mathrm{kDa}$. These data indicate effective crosslinking of MS4A13-2 molecules by BS3 and suggest that BS3 generates homophilic or heterophilic crosslinks with MS4A13-2 in acrosome-reacted spermatozoa.

\section{Effect of MS4A13-2 on fertilization}

As shown in Table 1, in an experiment using zona pellucida-intact oocytes, the rate of two-cell formation decreased in a dose-dependent manner on treatment with anti-MS4A13-2 antibody (extracellular region). The difference between experimental (treated with antiMS4A13-2 antibody (extracellular region)) and control groups (treated with TYH capacitation medium, preimmune serum or anti-MS4A13-2 antibody (C-terminus)) was significant $(P<0.05)$. As shown in Table 2 , in the experiment using zona pellucida-free oocytes, the rate of two-cell formation was not decreased by treatment with anti-MS4A13-2 antibody (extracellular region).

\section{Discussion}

In this study, we isolated 174 DNA fragments (under analysis) upregulated during the development of sperm heads in S. murinus testes. We found that one of the genes had high homology with one Suncus transcript, Ms4a13 (under analysis), and two mouse transcripts, Ms4a13-1 and Ms4a13-2. Mouse Ms4a13-2 mRNA was strongly expressed in the mouse testis and epididymis, and at much lower levels in the kidney, spleen, liver and heart; however, mouse Ms4a13-1 was undetectable in all organs examined. The expression of Ms4a13-2 mRNA in mouse testis was first detected at 2 weeks postpartum and continued to be expressed into adulthood.

Recent studies have reported that, among MS4A family members, MS4A5 (Hulett et al. 2001), MS4A13 (Turner et al. 2008) and MS4A14 (Xu et al. 2014) are specifically expressed in the testis; however, details of the localization and functions of MS4A5 and MS4A13 have not previously been revealed. In the rat, MS4A14 locates in the acrosome region of the sperm head and at the midpiece of the flagellum (Xu et al. 2014). Pretreatment of mature sperm with MS4A14 antibody during the IVF procedure caused a clear reduction in the normal fertilization rate (jia et al. 2010) and in vivo fertilization using transgenic males in which levels of testicular Ms4a14 mRNA were reduced by $30 \%$, with WT females, resulted in a reduced number of litters; the fertility rate declined to $34.48 \%$ using transgenic males, compared with $70.95 \%$ in the control group (Shi et al. 2010). We found that pretreatment of mature sperm with the anti-MS4A13-2 antibody during the IVF procedure caused a clear reduction in the normal fertilization rate of zona pellucida-intact oocytes with cumulus, whereas it had no significant effect on the fertilization rate of the zona pellucida-free oocytes without cumulus. These data suggest that MS4A13-2 may be involved in an 
Table 1 Effect of anti-MS4A13-2 antibodies on fertilization of mouse zona pellucida-intact oocytes.

\begin{tabular}{lccc}
\hline & & \multicolumn{2}{c}{ Two-cell formation* $(n=3)$} \\
\cline { 2 - 4 } Treatment & Concentration $(\mu \mathbf{g} / \mathbf{m L})$ & Total number of oocytes observed $^{\%}(\mathrm{mean} \pm \text { S.E.M. })^{\dagger}$ \\
\hline TYH (control) & - & 115 & $70.3 \pm 6.5^{\mathrm{a} 1}$ \\
Pre-immune (control) & 100 & 108 & $74.4 \pm 2.8^{\mathrm{a} 2}$ \\
mMS4A13-2 C-terminus (control) & 100 & 108 & $72.1 \pm 5.8^{\mathrm{a} 3}$ \\
mMS4A13-2 extracellular region & 25 & 74 & $43.1 \pm 10.8^{\mathrm{a} 4}$ \\
& 50 & 70 & $31.7 \pm 1.3^{\mathrm{a} 5}$ \\
\end{tabular}

*Two-cell formation was checked at $24 \mathrm{~h}$ after insemination. $\mathrm{t}, \mathrm{a} 1, \mathrm{a} 2, \mathrm{a} 3 \mathrm{vs}$ a4, a5, a6: $P<0.05$.

interaction with the zona pellucida or cumulus, but not oocytes, during fertilization.

MS4A family members share the topology of their transmembrane domains; however, they exhibit low sequence similarity. The regions demonstrating the greatest variation among MS4A proteins are those in the $\mathrm{N}$ - and $\mathrm{C}$-terminal cytoplasmic domains and the putative second extracellular loop (Ishibashi et al. 2001), suggesting that these regions may impart unique functional characteristics. Although MS4A13-2 and MS4A14 also share the same basic structure, there are large differences between their $\mathrm{N}$ - and $\mathrm{C}$-terminal domains and putative second extracellular loops; for example, MS4A13-2 has a very short $\mathrm{N}$-terminus and MS4A14 has a much longer C-terminal tail, including phosphorylation and glycosylation sites (Xu et al. 2014). Additionally, in molecular phylogenetic analysis of mouse MS4A family members using CLUSTALW (http:// www.genome.jp/tools/clustalw/), MS4A13-2 was found to have higher homology to MS4A1, MS4A3, MS4A4c, MS4A4d and MS4A9 than to MS4A5 and MS4A14. These data suggest that MS4A13-2 and MS4A14 may have diverse binding targets and different roles in fertilization.

In thisstudy, wefound that the localization of MS4A13-2 extended to the postacrosomal region and acrosomal cap of sperm heads within a maximum of 5 min after the acrosome reaction, whereas in spermatozoa freshly isolated from cauda epididymides and capacitated, it was limited to equatorial region. Furthermore, we found that the molecular size of MS4A13-2 did not alter before and after the acrosome reaction, indicating that MS4A13-2 was not cleaved on relocalization. The localization of several membrane proteins changes in spermatozoa after the acrosome reaction. Izumo1, the only candidate in sperm-egg fusion protein, is a type I membrane glycoprotein with one immunoglobulinlike domain and a putative $\mathrm{N}$-glycoside link motif, detectable on the inner and outer acrosomal membranes of the anterior acrosome before the acrosome reaction, and on the entire surface of the sperm head, including the equatorial region (Inoue et al. 2005), within a maximum of $30 \mathrm{~s}$ after the acrosome reaction (Satouh et al. 2012). Moreover, recent studies have reported that the molecular size and amount of unphosphorylated Izumo1 remained unchanged by the acrosome reaction, whereas that of phosphorylated Izumo1 was greatly diminished after the acrosome reaction (Ellerman et al. 2009). The specific loss of phosphorylated Izumo1 may be due to its localization on the outer acrosomal membrane, which is lost as vesicles after the acrosome reaction, or to the dephosphorylation of Izumo1. SPACA1, an important protein that functions to shape the sperm head and in sperm-egg fusion, localizes to the inner acrosomal membrane of the entire acrosome and on the outer acrosomal membrane of the equatorial region before the acrosome reaction, and remains on the inner acrosomal membrane in capacitated and acrosome-reacted spermatozoa (Fujihara et al. 2012). Since MS4A13-2 shows somewhat similar localization changes to SPACA1 during spermatogenesis, and is detectable on the entire surface of the sperm head, including the equatorial region, immediately after the acrosome reaction, it may have a similar role to those of SPACA1 and Izumo1 in the testis and during fertilization. However, how MS4A13-2 relocates to the entire surface of the sperm head and how it behaves during fertilization remain to be elucidated.

In conclusion, we demonstrate that mouse MS4A132 , but not MS4A13-1, is a constituent molecule of the outer acrosomal membrane of the equatorial region of fresh sperm heads. In addition, the expression of MS4A13-2 extends to whole sperm heads, including the postacrosomal region and acrosomal cap, after the acrosome reaction. Current evidence suggests that some MS4A family members may form hetero/homooligomers and function as ion channel/adaptor proteins

Table 2 Effect of anti-MS4A13-2 antibody on fertilization of mouse zona pellucida-free oocytes.

\begin{tabular}{lccc}
\hline & & \multicolumn{2}{c}{ Two-cell formation* $(n=3)$} \\
\cline { 2 - 3 } Treatment & Antibody concentration $(\mu \mathrm{g} / \mathrm{mL})$ & Total number of oocytes observed & $\%($ mean \pm S.E.M.) \\
\hline TYH (control) & - & 102 & $76.8 \pm 3.1$ \\
mMS4A13-2 extracellular region & 100 & 126 & $77.4 \pm 1.8$ \\
\hline
\end{tabular}

*Two-cell formation was checked at $24 \mathrm{~h}$ after insemination. 
to facilitate intracellular protein-protein interactions, with important regulatory roles in cellular growth, survival and activation (Eon Kuek et al. 2016). As MS4A13-2 was detected at $19 \mathrm{kDa}$ (monomer), $40 \mathrm{kDa}$ and the bands larger than $40 \mathrm{kDa}$ in the presence of BS3, MS4A13-2 may also form hetero/homo-oligomers, such as dimers and multimer, and have an important role in fertilization. Further studies of MS4A13-2 will provide additional information about, and understanding of, the molecular complexity involved in the mechanism of fertilization. Furthermore, gene knockout models could facilitate elucidation of the function of MS4A13-2.

\section{Supplementary data}

This is linked to the online version of the paper at http://dx.doi.org/10.1530/REP-17-0477.

\section{Declaration of interest}

The authors declare that there is no conflict of interest that could be perceived as prejudicing the impartiality of the research reported.

\section{Funding}

This work was supported by the Kyushu University Research Activity Support Program.

\section{Acknowledgements}

The authors are very grateful to Dr S Oda and Dr T Jogahara of the Laboratory of Animal Management and Resources, Department of Zoology, Faculty of Science, Okayama University of Science, for supplying the musk shrew. The authors would like to thank Editage (www.editage.jp) for English language editing.

\section{References}

Awano M, Kawaguchi A \& Mohri H 1993 Lipid composition of hamster epididymal spermatozoa. Journal of Reproduction and Fertility 99 375-383. (doi:10.1530/ jrf.0.0990375)

Bangur CS, Johnson JC, Switzer A, Wang YH, Hill B, Fanger GR, Wang T \& Retter MW 2004 Identification and characterization of L985P, a CD20 related family member over-expressed in small cell lung carcinoma. International Journal of Oncology 25 1583-1590. (doi:10.3892/ ijo.25.6.1583)

Bedford JM, Cooper GW, Phillips DM \& Dryden GL 1994 Distinctive features of the gametes and reproductive tracts of the Asian musk shrew, Suncus murinus. Biology of Reproduction 50 820-834. (doi:10.1095/ biolreprod50.4.820)

Bubien JK, Zhou LJ, Bell PD, Frizzell RA \& Tedder TF 1993 Transfection of the CD20 cell surface molecule into ectopic cell types generates a $\mathrm{Ca} 2+$ conductance found constitutively in B lymphocytes. Journal of Cell Biology 121 1121-1132. (doi:10.1083/jcb.121.5.1121)

Chinami M, Yano Y, Yang X, Salahuddin S, Moriyama K, Shiroishi M, Turner H, Shirakawa T \& Adra CN 2005 Binding of HTm4 to cyclindependent kinase (Cdk)-associated phosphatase (KAP) $\cdot \mathrm{Cdk} 2 \cdot \mathrm{cyclin} \mathrm{A}$ complex enhances the phosphatase activity of KAP, dissociates cyclin
A, and facilitates KAP dephosphorylation of Cdk2. Journal of Biological Chemistry 280 17235-17242. (doi:10.1074/jbc.M413437200)

Cruse G, Kaur D, Leyland M, \& Bradding P 2010 A novel Fc-epsilonRI beta-chain truncation regulates human mast cell proliferation and survival. FASEB Journal 24 4047-4057. (doi:10.1096/fj.10-158378)

Dombrowicz D, Lin S, Flamand V, Brini AT, Holler BH \& Kinet JP 1998 Allergy-associated FcRb is a molecular amplifier of IgE- and IgG mediated in vivo responses. Immunity 8 517-529.

Donato JL, Ko J, Kutok JL, Cheng T, Shirakawa T, Mao XQ, Beach D, Scadden DT, Sayegh MH \& Adra CN 2002 Human HTm4 is a hematopoietic cell cycle regulator. Journal of Clinical Investigation 109 51-58. (doi:10.1172/JCI14025)

Ellerman DA, Pei J, Gupta S, Snell WJ, Myles D \& Primakoff P 2009 Izumo is part of a multiprotein family whose members form large complexes on mammalian sperm. Molecular Reproduction and Development $\mathbf{7 6}$ 1188-1199. (doi:10.1002/mrd.21092)

Eon Kuek L, Leffler M, Mackay GA \& Hulett MD 2016 The MS4A family: counting past 1,2 and 3. Immunology and Cell Biology 94 11-23. (doi:10.1038/icb.2015.48)

Fujihara Y, Satouh Y, Inoue N, Isotani A, Ikawa M \& Okabe M 2012 SPACA1-deficient male mice are infertile with abnormally shaped sperm heads reminiscent of globozoospermia. Development 139 3583-3589. (doi:10.1242/dev.081778)

Greer PL, Bear DM, Lassance JM, Bloom ML, Tsukahara T, Pashkovski SL, Masuda FK, Nowlan AC, Kirchner R, Hoekstra HE et al. 2016 A Family of non-GPCR chemosensors defines an alternative logic for mammalian olfaction. Cell 165 1734-1748. (doi:10.1016/j.cell.2016.05.001)

Hollingworth P, Harold D, Sims R, Gerrish A, Lambert JC, Carrasquillo MM, Abraham R, Hamshere ML, Pahwa JS, Moskvina V, et al. 2011 Common variants at ABCA7, MS4A6A/MS4A4E, EPHA1, CD33 and CD2AP are associated with Alzheimer's disease. Nature Genetics 43 429-435. (doi:10.1038/ng.803)

Hulett MD, Pagler E, Hornby JR, Hogarth PM, Eyre HJ, Baker E, Crawford J, Sutherland GR, Ohms SJ \& Parish CR 2001 Isolation, tissue distribution, and chromosomal localization of a novel testis-specific human four transmembrane gene related to CD20 and Fc-epsilon-RI-b. Biochemical and Biophysical Research Communications 280 374-379. (doi:10.1006/ bbrc.2000.4088)

Inoue N, Ikawa M, Isotani A \& Okabe M 2005 The immunoglobulin superfamily protein Izumo is required for sperm to fuse with eggs. Nature 434 234-238. (doi:10.1038/nature03362)

Ishibashi K, Suzuki M, Sasaki S \& Imai M 2001 Identification of a new multigene four-transmembrane family (MS4A) related to CD20, HTm4 and $b$ subunit of the high-affinity IgE receptor. Gene 264 87-93. (doi:10.1016/S0378-1119(00)00598-9)

Ito C \& Toshimori K 2016 Acrosome markers of human sperm. Anatomical Science International 91 128-142. (doi:10.1007/s12565-015-0323-9)

Jia XF, Zhou M, Lin JF, Shi WL, Zhang XD \& Shi HJ 2010 Role of SP3111 protein in fertilization and early embryo development in mice. Zhonghua Nan Ke Xue 16 14-19.

Kaneko T, lida H, Bedford JM \& Mori T 2001 Spermatozoa of the shrew, Suncus murinus, undergo the acrosome reaction and then selectively kill cells in penetrating the cumulus oophorus. Biology of Reproduction 65 544-553. (doi:10.1095/biolreprod65.2.544)

Koslowski M, Sahin U, Dhaene K, Huber C \& Türeci O 2008 MS4A12 is a colon-selective store-operated calcium channel promoting malignant cell processes. Cancer Research 68 3458-3466. (doi:10.1158/00085472.CAN-07-5768)

Kutok JL, Yang X, Folkerth R \& Adra CN 2011 Characterization of the expression of HTm4 (MS4A3), a cell cycle regulator, in human peripheral blood cells and normal and malignant tissues. Journal of Cellular and Molecular Medicine 15 86-93. (doi:10.1111/j.15824934.2009.00925.x)

Liang Y \& Tedder TF 2001 Identification of a CD20-, FC-epsilon-RI-beta-, and HTm4-related gene family: sixteen new MS4A family members expressed in human and mouse. Genomics 72 119-127. (doi:10.1006/ geno.2000.6472)

Liang Y, Buckley TR, Tu L, Langdon SD \& Tedder TF 2001 Structural organization of the human MS4A gene cluster on chromosome $11 q 12$. Immunogenetics 53 357-368. (doi:10.1007/s002510100339)

Lin S, Cicala C, Scharenberg AM \& Kinet JP 1996 The FceRIß subunit functions as an amplifier of FceRly-mediated cell activation signals. Cell 85 985-995. (doi:10.1016/S0092-8674(00)81300-8) 
Naj AC, Jun G, Beecham GW, Wang LS, Vardarajan BN, Buros J, Gallins PJ, Buxbaum JD, Jarvik GP, Crane PK et al. 2011 Common variants at MS4A4/ MS4A6E, CD2AP, CD33 and EPHA1 are associated with late-onset Alzheimer's disease. Nature Genetics 43 436-441. (doi:10.1038/ng.801)

Okabe M 2014 Mechanism of fertilization: a modern view. Experimental Animals 63 357-365. (doi:10.1538/expanim.14-0026)

Polyak MJ, Li H, Shariat N \& Deans JP 2008 CD20 homo-oligomers physically associate with the $\mathrm{B}$ cell antigen receptor. Dissociation upon receptor engagement and recruitment of phosphoproteins and calmodulin-binding proteins. Journal of Biological Chemistry 283 18545-18552. (doi:10.1074/ jbc.M800784200)

Satouh Y, Inoue N, Ikawa M \& Okabe M 2012 Visualization of the moment of mouse sperm-egg fusion and dynamic localization of IZUMO1. Journal of Cell Science 125 4985-4990. (doi:10.1242/jcs.100867)

Shirakawa T, Li A, Dubowitz M, Dekker JW, Shaw AE, Faux JA, Ra C, Cookson WO \& Hopkin JM 1994 Association between atopy and variants of the beta subunit of the high-affinity immunoglobulin $E$ receptor. Nature Genetics 7 125-130. (doi:10.1038/ng0694-125)

Shi W, Shi T, Chen Z, Lin J, Jia X, Wang J \& Shi H 2010 Generation of sp3111 transgenic RNAi mice via permanent integration of small hairpin RNAs in repopulating spermatogonial cells in vivo. Acta Biochimica et Biophysica Sinica 42 116-121. (doi:10.1093/abbs/gmp110)

Stein KK, Primakoff P \& Myles D 2004 Sperm-egg fusion: events at the plasma membrane. Journal of Cell Science 117 6269-6274. (doi:10.1242/jcs.01598)

Tanii I, Araki S \& Toshimori K 1994 Intra-acrosomal organization of a 90-kilodalton antigen during spermiogenesis in the rat. Cell and Tissue Research 277 61-67. (doi:10.1007/BF00303081)

Tedder TF \& Engel P 1994 CD20: a regulator of cell-cycle progression of B lymphocytes. Immunology Today 15 450-454. (doi:10.1016/01675699(94)90276-3)
Toshimori K, Saxena DK, Tanii I \& Yoshinaga K 1998 An MN9 antigenic molecule, Equatorin, is required for successful sperm-oocyte fusion in mice. Biology of Reproduction 59 22-29. (doi:10.1095/ biolreprod59.1.22)

Toyoda Y, Yokoyama M \& Hoshi T 1971 Studies on the fertilization of mouse eggs in vitro. Japanese Journal of Animal Reproduction $\mathbf{1 6}$ 147-157. (doi:10.1262/jrd1955.16.147)

Turner LM, Chuong EB \& Hoekstra HE 2008 Comparative analysis of testis protein evolution in rodents. Genetics 179 2075-2089. (doi:10.1534/ genetics.107.085902)

Xu H, Yan Y, Williams MS, Carey GB, Yang J, Li H, Zhang GX \& Rostami A 2010 MS4a4B, a CD20 homologue in T cells, inhibits T cell propagation by modulation of cell cycle. PLOS ONE 5. (doi:10.1371/journal. pone.0013780)

Xu Y, Liu M, Gu YH, Jia XF, Chen YM, Santos M, Wu AZ, Zhang XD, Shi HJ \& Chen CL 2014 CDNA cloning and localization of Sp3111 (also called Ms4a14) in the rat testis. Reproduction 148 81-86. (doi:10.1530/REP14-0087)

Zuccolo J, Bau J, Childs SJ, Goss GG, Sensen CW \& Deans JP 2010 Phylogenetic analysis of the MS4A and TMEM176 gene families. PLOS ONE 5 e9369. (doi:10.1371/journal.pone.0009369)

Received 31 July 2017

First decision 25 August 2017

Revised manuscript received 11 September 2017

Accepted 2 October 2017 